\title{
Estudios recientes sobre la composición del Pentateuco
}

La hipótesis documentaria, formulada hacia el 1876 por J. Wellhausen, ha reinado indiscutida en el presente siglo. Era fruto de la crítica literaria, método empleado desde que comenzó la investigación científica de la Biblia. Ella se impuso frente a otras hipótesis de una manera tan rotunda, que las siglas J,E,D y $P$ pasaron a los libros de divulgación.

La hipótesis documentaria se presentó como hija de la crítica literaria; sin embargo, no es su conclusión necesaria. Para explicar las incoherencias, contradicciones, diferencias de estilo y vocabulario, duplicados, etc., que se sorprenden en el Pentateuco, pueden formularse otras hipótesis; $y$ de hecho otras explicaciones se dieron. Si la hipótesis documentaria se impuso frente a otras teorías, fue porque se pensaba que ella explicaba mejor el estado actual del Pentateuco, y, desde luego, por su sencillez. Y es bien sabido que en el terreno de las ciencias, las hipótesis sencillas tienen mayor grado de verosimilitud, precisamente porque no necesitan otras hipótesis.

Esta posición de privilegio no la perdió, ni siquiera cuando H. Gunkel introdujo el método de la Historia de las Formas en la explicación del Pentateuco. Evidentemente hubo que reformar algunos puntos de la hipótesis wellhauseniana. El J, por ejemplo, ya no podía ser considerado como autor de lo que escribe. La figura de compilador o de colector le cuadraba mejor. Desde el momento en que el material del Pentateuco ha tenido una historia preliteraria, el $\mathbf{J}$ y el resto de las fuentes, ya no pueden ser considerados como autores del material, sino como compiladores que hilvanan los relatos con más o menos perfección. A Gunkel no se le ocurrió pensar que su teoría podía hacer peligrar la hipótesis documentaria. Tampoco G. von Rad y M. Noth, que continuaron el método de Gunkel, querían poner en duda la hipótesis documentaria; sin embargo, no cabe duda de que con su proceder, la hipótesis sufre un trastorno grave. En efecto, los argumentos que desde Wellhausen venían usándose para distinguir las fuentes (distinto nombre para designar a la Divi- 
nidad, diferencias de estilo y vocabulario, duplicados, contradicciones, etc.) pierden mucho de su fuerza. La razón es clara: estas diferencias pueden ser debidas al estado del material preexistente y no a la redacción de los documentos. En otras palabras, lo que se creía ser indicio indudable de la redacción del $\mathrm{J}$, por ejemplo, puede no serlo.

La debilidad de la hipótesis documentaria, por otra parte, ha sido congénita. Lo cual es normal, tratándose de una hipótesis. La mayoría de los exégetas no ponían en duda la existencia de las fuentes. Pero casi desde el comienzo se manifestaron ciertas desavenencias. Así el E para alguno era una pura fantasía ${ }^{1}$. Otros dividían el $\mathrm{J}$ en varias fuentes. Pero aun prescindiendo de esto y limitándose a los autores fieles a la división del Pentateuco en cuatro fuentes, el consenso terminaba muy pronto. Bastaba leer, por ejemplo, un par de comentarios al libro del Éxodo para darse cuenta que no se coincidía en la asignación de textos a las fuentes. Resulta relativamente fácil distinguir las partes pertenecientes a $\mathrm{P}$; pero separar las fuentes antiguas, sobre todo a partir del Éxodo, era una empresa desesperada ${ }^{2}$. Faltaban también criterios para distinguir las partes legislativas y asignarlas a las fuentes.

Por estas razones no se coincidía y no se coincide aún hoy en la imagen que cada uno se hace de los documentos del Pentateuco. El J de G. von Rad es bien diferente del $\mathbf{J}$ de $\mathbf{M}$. Noth, por no citar más que un ejemplo. La originalidad del proyecto del $\mathrm{J}$, que tanto alaba $\mathrm{G}$. von $\mathrm{Rad}$, no tiene razón de ser, si se admite con M. Noth que existió la Grundschrift, anterior al J y a $\mathrm{E}^{3}$.

A pesar de todas estas dificultades, la hipótesis documentaria no se ponía en duda. Se intentaba mejorar desde el interior, manteniendo siempre el principio de la repartición en fuentes.

$\because$ Pero he aquí que desde el año 1975 se asiste a una serie de ataques, que socaban lo que hasta ahora se tenía por inconcuso. Los ataques provienen de diversos campos y llegan a conclusiones diferentes e incluso contrarias, aunque se mantienen ciertos puntos de coincidencia entre ellos. Una coincidencia curiosa es arremeter contra el $\mathrm{J}$, que es, sin duda alguna, el pilar básico de la hipótesis documentaria.

Veamos algunas de estas opiniones recientes.

1. P. Volz-W. Rudolph, Der Elohist als Erzähler. Ein Irrweg der Pentateuchkritik? An der Genesis erläutert. BZAW, 63. Giessen 1933; S. MowINCKEL, Erwägungen zur Pentateuchquellenfragen. Trondheim, 1964.

2. Esto es comúnmente señalado por todos. Véase, por ejemplo, W.H. SCHMIDT, Introducción al antiguo testamento, Salamanca, 1983, p. 73.

3. G. Von RAD, «El problema morfogenético del Hexateuco»: Estudios sobre el Antiguo Testamento. Salamanca, 1976, 11-80, especialmente 71-76. M. NoTH, Ueberlieferungsgeschichte des Pentateuch. Stuttgart, 1948, 2 ed. 40-44. 


\section{La opinión de J. van Seters ${ }^{4}$}

No nos interesa particularmente aquí la primera parte de su libro, pues en ella no es atacada la hipótesis documentaria. Ataca, más bien, una cierta manera de pensar según la cual la arqueología podría aportar material para encuadrar la historia patriarcal en el marco de la historia general del Medio Oriente. La escuela americana de Allbright se valía de la arqueología para defender la historicidad fundamental de las tradiciones patriarcales. La filología aclara los nombres de los patriarcas, y a través de los nombres puede concluir a la etnia a la que pertenecían los patriarcas; la historia profana puede ofrecer un marco cronológico para la migración de los antepasados de Israel; las costumbres y leyes recogidas en los documentos extrabíblicos ilustran de alguna manera los relatos del Génesis. Comparando las tradiciones patriarcales con la información así recogida, habían concluido que la época que mejores paralelos ofrece para encajar la época patriarcal es la primera mitad del II milenio, o mejor, los primeros siglos del II milenio.

J. van Seters en la primera parte pretende destruir todas estas «pruebas» arqueológicas. Según él, tales indicios son muy vagos y universales, de tal manera que se dan también en el primer milenio. Antes que J. van Seters, ya Thompson ${ }^{5}$ en un libro muy erudito, había afirmado lo mismo. En este punto estos dos autores tienen mucha razón. Las pruebas arqueológicas deben manejarse con suma prudencia. Pero J. van Seters da un paso más: los mejores paralelos para Abrahán se dan en la literatura extrabíblica del s. VI a.C., es decir, durante el destierro. Concretamente ofrece un cúmulo de comparaciones con textos neoasirios, neobabilonios, persas y egipcios, que son todos posteriores al s. VII.

En este punto J. van Seters va más allá de lo debido. Si los paralelos son universales, entonces no valen para nadie; tampoco para él. Habría que preguntarse si él no cae en el defecto de los autores que combate: si estos últimos primaban las primeras apariciones de los paralelos, J. van Seters da preferencia siempre a los paralelos que convienen a sus tesis. Esto le reprocha Thompson con toda razón ${ }^{6}$.

Pero dejemos este punto que aquí no nos interesa particularmente, aunque ya se prevé por dónde se va a dirigir. Casi las dos terceras partes del libro están dedicadas a las cuestiones literarias de Gen 12-26, es decir, a las tradicio-

4. J. van SETERS, Abraham in History and Tradition. New Haven-London, 1975.

5. T.L. THOMPSON, The Historicity of the patriarchal Narratives. The Quest for the historical Abraham. BZAW, 133, Berlin, 1974.

6. (.T.L. ThompSon, «A new Attempt to date the Patriarchal Narratives»: Journal of the American Oriental society, 98 (1978) 76-84. 
nes patriarcales referentes a Abrahán. Es aquí donde se enfrenta abiertamente con la hipótesis documentaria y donde propone una nueva teoría. El análisis es ciertamente original y nada común en la exégesis actual. He aquí los puntos principales de su hipótesis:

a) Primeramente hace una crítica rigurosa y severa de todo cuanto se ha dicho desde Wellhausen para acá; y por cierto rechaza las conclusiones tanto de la hipótesis documentaria como de la Historia de las Formas. Si desde Wellhausen se admiten documentos independientes de los cuales se compone el Pentateuco actual, J. van Seters rechaza decididamente esta independencia supuesta de las fuentes. Él, como todos los críticos, ve en el texto actual, incoherencias, diferencias de estilo, etc., pero este fenómeno tiene otra explicación.

Rechaza también la hipótesis de Gunkel, es decir, no admite la existencia de relatos procedentes de la tradición oral, si no es acaso un par de leyendas folklóricas intemporales. La existencia de tradiciones orales es un supuesto artificial o dogma crítico que se sustenta en argumentos que no existen. De nada valen para él las razones invocadas desde Gunkel para acá con las que se pretendía probar la existencia de tales tradiciones orales. No vale la comparación con las sagas islandesas, pues éstas no tienen carácter familiar, sino que son obras literarias complejas. Las leyendas cultuales no tienen la función de legitimar los santuarios que los israelitas usan; por su parte, las invocaciones del «dios del padre» son construcciones tardías. Finalmente las promesas patriarcales son secundarias, redaccionales y fueron compuestas por el J para crear un lazo de unión entre los relatos patriarcales y el resto del Pentateuco.

Para hacer esta afirmación, aduce un argumento que en principio parece contradictorio. Se apoya en las leyes épicas de A. Olrik. Y cita a este autor con el fin de distinguir la tradición oral de la escrita. Solamente, según J. van Seters, los relatos que se conforman con las normas escénicas formuladas por Olrik pueden remontar a una tradición oral. Las reglas que dio Olrik son conocidas: acción reducida a tres personajes a lo sumo, aunque en escena sólo intervienen dos al mismo tiempo; concentración en el personaje principal; tensión que sube, llega a su clímax y luego desciende; el final mitiga la tensión habida. Según J. van Seters sólo Gen 12,10-20 y 16,1-3a. 4-9.11ab cumplen estas condiciones. Luego, según él, sólo estos dos relatos pueden remontar a una tradición oral. Cosa que, por otra parte, carece de excesiva importancia, pues en su origen se trataba de motivos del folklore universal.

b) ¿Cómo explica el origen del Pentateuco? Dado que no existen tradiciones preliterarias, forzoso le será admitir una composición literaria de los relatos actuales. Sería así volver a la hipótesis documentaria clásica e imaginar a los redactores no como compiladores, sino como verdaderos autores de lo que 
escriben. Pero J. van Seters marca las diferencias en seguida. No ha habido fuentes independientes. Hay ciertamente estratos literarios diversos, pero estos estratos se han ido acumulando unos detrás de otros en el curso del tiempo: un estrato antiguo es reinterpretado, reelaborado y completado por el siguiente. Gráficamente diríamos que los autores se suceden en la mesa del escritorio, queriendo reinterpretar y completar lo escrito anteriormente. Así el material fue creciendo con nuevas leyendas y afabulaciones. Sería una especie de hipóteis complementaria, que tuvo sus adeptos en el siglo pasado.

Concretamente cree poder distinguir cinco estratos en los relatos acerca de Abrahán:

1) Un primer estrato comprende unos cuarenta versículos y sería pre-J: Gen 12, 1-4a. 6a-7. 10-20; 13, 1-2; 16, 1-3a. 4-9. 11ab. 12. 18; 18, 1a. 10-14; 21, 2. 6-7.

2) Un segundo estrato también pre-J, que recibe el nombre de E, comprendería 20, 1-17; 21, 25-26. 28-31a.

Acerca de la fecha de estos dos estratos, J. van Seters no se pronuncia abiertamente, pero todo hace suponer que los coloca al final de la monarquía.

3) El tercer estrato es el más importante. Le denomina con la sigla $\mathbf{J}$ y comprende: 12 , 2-3. 6b. 8-9; 13, 3-5. 7-17; 15; 16, 7b. 10. 11c. 13-14; 18, 1b-9. 15-19, 38; 20, 1aa; 21, 1. 8-24. 27. 31b-34; 22; 24; 25, 1-6. 11; 26.

4) El cuarto estrato pertenece a $P$, y es posterior al destierro: 11, 26-32; 12 , 4b-5; 13,6; 16, 3b. 15-16; 17; 21, 3-5; 23; 25, 7-10.

5) Finalmente un último estrato, perteneciente a post-P, al cual asigna el cap. 14 .

Este cuadro, prescindiendo de las siglas, no debiera extrañar mucho en principio. Los textos atribuidos a $\mathrm{P}$, así como el carácter especial del cap. 14, son cosas que no extrañan. Tampoco es digno de notar que atribuya tan pocos textos a E. Es bastante general atribuirle más textos, pero conviene advertir que hay otros autores que no encuentran a $\mathrm{E}$ en las tradiciones patriarcales, como, por ejemplo, C. Westermann ${ }^{7}$. Sí es curioso que haga depender a J. del E., pero estas siglas no recubren lo que con ellas se designaba en la teoría documentaria.

Más importante y más chocante es el análisis que hace de las perícopas para probar sus afirmaciones. A esta labor dedica gran parte del libro. El lector se interesa especialmente por aquellos relatos que son duplicados, porque es aquí donde mejor se aprecia la función de la hipótesis complementaria que J. van Seters defiende. No se olvide que los duplicados eran una de las razones poderosas para admitir fuentes independientes. J. van Seters se esforzará por

7. C. Westermann, Genesis. 2 Teilband, Gen 12-36. BK I/2. Neukirchen 1981, 696. 
demostrar que los relatos paralelos no son tales, sino complementos sucesivos en el sentido de que el siguiente conoce el texto anterior que reinterpreta y reelabora.

El conocido episodio en que el patriarca hace pasar a su esposa por hermana $(12,10-20 ; 20,1-18 ; 26,2-11)$ es ilustrativo de su manera de entender el crecimiento de la tradición. Precisamente este caso, es el que ha provocado y desencadenado el estudio de J. van Seters. Los tres relatos dependen entre sí. Gen 12 sería el relato más antiguo: una especie de cuento divertido. Gen 20 no es ni siquiera relato, sino una reflexión teológica que intenta corregir moralmente la escabrosidad del relato primitivo. No es una variante, sino una corrección que supone el relato de Gen 12 e incluso lo supone en su lugar actual. Gen 26 conoce los dos relatos anteriores. Las razones que da son los contactos literarios que nota, así como los motivos ciegos, etc. Lo que no explica J. van Seters es por qué el $\mathrm{J}$ en el cap. 26 vuelve otra vez con el mismo tema, si ya había dicho lo que tenía que decir en Gen 12, 10-20.

A continuación examina los relatos restantes que son explicados de una manera semejante.

Finalmente J. van Seters trata de encontrar el Sitz im Leben de las tradiciones patriarcales. Para él J, que es el estrato más extenso, pertenece al destierro. El exilio explica suficientemente las preocupaciones teológicas que manifiestan las tradiciones patriarcales. Así la intercesión de Abrahán 18,23-32 sería un exponente del problema discutido durante el destierro: si algunos justos podrán salvar a la comunidad. Este problema, como se sabe, es discutido por Ezequiel. En el cap. 15 encuentra numerosos indicios de su origen exílico: el oráculo de salud y la mención del salario acerca este cap. al II Isaías. El rito de la alianza descrito en el v. 9 no se halla atestiguado antes de Jeremías $(34,18)$. El v. 8 es la expresión de la nueva alianza deseada y exigida por la comunidad exílica. Los vv. 13-16 integran el éxodo en la tradición patriarcal y constituyen un mensaje de esperanza dirigido a los desterrados: el exilio durará sólo hasta la cuarta generación. Gen 21,12 traspone la elección a los patriarcas, idea compartida por el II Isaías. Gen 22 expresa una ruptura de la teología de Sión después de la destrucción del templo. Gen 24 manifiesta la preocupación de preservar la pureza de la raza y anhela el ideal de una experiencia religiosa no cultual. Gen 34 es una polémica contra los samaritanos. Gen 26 tiene como objetivo reivindicar los territorios del Negueb perdidos durante el destierro.

Hemos querido resumir en breve los puntos de vista del autor. No quisiéramos dar la impresión de ligereza porque ofrezcamos solamente algunas muestras de lo que él dice. El lector deberá recurrir al libro, porque su lectura merece la pena. 
A nuestro parecer, la hipótesis de J. van Seters presenta dos puntos especialmente graves: el primero es el rechazo de toda tradición oral preexistente. Desde Gunkel para acá se viene afirmando y suponiendo sin más la existencia de tales tradiciones orales. J. van Seters para negarlo se apoya en A. Olrik. Este argumento es muy débil. Olrik se refería a los episodios o narraciones de tinte dramático. Por lo que sus leyes no valen para relatos que no reúnan estas condiciones, como por ejemplo, los itinerarios, genealogías, etc. El libro de R.R. Wilson prueba suficientemente, a nuestro juicio, que las genealogías no se pueden explicar sin su prehistoria oral ${ }^{8}$. Además, las leyes de Olrik exponen el maximum, es decir, relatos que respeten estas leyes, se conservan mejor en la tradición oral, pero en ningún caso aseguran que se pueda inferir de la forma narrativa (forma más o menos artificial, estructura más o menos acertada), al modo de transmisión oral o escrita. No siempre ha pasado a la forma escrita, la mejor forma literaria oral. Por otra parte, cuando se habla de «formas simples», siempre se refiere uno a las formas simples en potencia; que, precisamente, no existen. Lo que existen son relatos concretos, que son encarnaciones de las formas simples y no siempre responden al esquema ideal o potencial de una forma simple. J. van Seters parece no haber hecho caso de los últimos estudios sobre las formas literarias. Al fin y al cabo, el artículo de Olrik, que es de 1912, no es la última palabra sobre el tema ${ }^{9}$.

Un segundo punto grave de J. van Seters es el rechazo de toda tradición oral. Bajo este aspecto, no parece haber tenido en cuenta y por tanto no ha refutado uno de los principales argumentos que aducen los partidarios de la tradición oral. Quien lea las tradiciones patriarcales observa inmediatamente grandes diferencias entre el ciclo de Abrahán y el ciclo de Jacob. Las narraciones de Abrahán son cortas, están dominadas por la relación padres-hijos, tienen un carácter elemental: hablan de la vida y de la muerte, de la obtención de descendencia. Por el contrario, las narraciones de Jacob son más largas, están dominadas por la relación entre hermanos y el carácter es más complicado: surgen instituciones, pactos, relaciones entre pueblos. Estas diferencias no se pueden explicar mediante la crítica literaria, ya que tanto un ciclo como otro se atribuyen a las mismas fuentes. La única explicación posible es recurrir a la tradición oral, a los distintos transmisores, a la diferente cultura de los portadores de tales tradiciones ${ }^{10}$.

No quisiéramos dejar de mencionar la tardía fecha a que atribuye la ma-

8. R.R. Wilson, Genealogy and History in the Old Testament. A history of the Form and Function of the old testament Genealogies in their Near Eastern Context. Yale, 1972.

9. A. de Pury, Promesse Divine et legende cultuelle dans le cycle de Jacob. Genèse 28 et les traditions patriarcales. Paris 1975, vol. II, 464-7.

10. C. WESTERMANN, ob. cit. 9. 
yor parte de las tradiciones patriarcales. Prácticamente todo es exílico o posexílico. No parece que haya pensado mucho en las razones que A. Alt y M. Noth aducen para suponer una alta antigüedad a las narraciones patriarcales. Éstas son narraciones de antepasados. Sólo, pues, tienen interés para los que se consideran sus descendientes. Ahora bien, puesto que ninguno de estos antepasados lleva el nombre de las tribus del Israel histórico, lógico es concluir que estos antepasados, o, al menos, los que las han transmitido, remontan a la etapa anterior a la formación de las tribus de Israel, es decir, a la prehistoria o protohistoria de Israel. Bajo este punto de vista habría que preguntarse qué interés podrían tener los israelitas en inventarse semejante tradición durante el destierro. Exponer unos cuantos puntos doctrinales no parece ser razón suficiente. Ezequiel y otros profetas trataron tales temas, sin necesidad de inventarse unos antepasados ${ }^{11}$.

\section{2) La opinión de H.H. Schmidt ${ }^{12}$}

Como el título indica, el ataque de Schmidt se dirige especialmente contra el J, cuya existencia en realidad no niega, pero lo transforma totalmente. En dos puntos principalmente cambia la imagen que de él se tiene: su naturaleza y su fecha. Aunque conserve el nombre tradicional, el J para Schmidt no es una fuente o documento, obra de un autor o compilador, sino un amplio proceso de redacción e interpretación teológica, emparentada con el Deut o Dtr, posterior a los profetas preexílicos ${ }^{13}$. La fecha en que se puso por escrito sería el final de la monarquía o primera etapa del destierro.

Las razones que invoca, son unas, de orden genérico: le parece difícil imaginarse al J, escritor religioso, componiendo su obra en una época de fuerte sincretismo y paganización de la religión de Israel; pensar que la época de Salomón fue una era de ilustración, como cree G. von Rad, es una teoría de la que no existen pruebas. De otra parte, antes de la teología de la historia de la que el $\mathbf{J}$ es considerado como primer autor, en Israel nació una literatura sapiencial, no interesada en los hechos históricos.

Seguidamente aduce una serie de razones más específicas. Y en este apar-

11. A. de PURY, Recensión de las obras de Thompson y J. van Seters en Revue Biblique, 85 (1978) 589-618, especialmente 611.

12. H.H. SCHMIDT, Der sogenannte Jahwist. Beobachtungen und Fragen zur Pentateuchforschung. Zürich, 1976.

13. Schmidt es más contundente frente a la hipótesis documentaria en un artículo posterior publicado en Journal for the Study of the Old Testament 3 (1977). Este número de la revista está dedicado íntegramente al estudio de la composición del Pentateuco. En él escriben J. van Seters, H.H. Schmidt, R. Rendtorff y otros autores. 
tado analiza los temas principales del J: vocación de Moisés, plagas de Egipto, paso del Mar Rojo, algunos relatos de la tradición del desierto, tradiciones del Sinaí, promesas patriarcales. Los tres temas primeros son examinados personalmente. Y ya se prevé cuál va a ser su labor: acentuar el paralelismo del J con la literatura del Deut o escritos influenciados por él, afirmando la dependencia o cercanía en el tiempo del primero sobre el segundo. En cuanto a los tres temas restantes se guía en cada caso de estudios recientes, extrayendo las conclusiones que interesan a su teoría. Así, para las tradiciones del desierto se basa en V. Fritz ${ }^{14}$; para las tradiciones del Sinaí se vale de L. Perlitt, de E. Zenger y de A. Reich ${ }^{15}$.

Veamos las razones más concretamente:

La vocación de Moisés (Ex 3) presupone la existencia de un género literario que él llama «vocación profética»; por lo que cabe concluir que no puede ser anterior a Jeremías. Esta dependencia explicaría mejor el texto de Ex 3 que no el recurso a un esquema de vocación del «salvador», como hace W. Richter. El endurecimiento del faraón sería un pensamiento en estrecha dependencia de Is 6. Igualmente la sección de las plagas contiene ideas y conceptos propios de los profetas y suponen su predicación. El paso del Mar Rojo tiene estrechas relaciones con Is 7,11ss. En ambos textos hay un oráculo de salvación. En el texto profético el oráculo está dirigido a su destinatario original: el rey. En el Pentateuco está ya dirigido a los patriarcas o en el marco de la institución de la guerra santa, institución tan estimada por el Deut.

En las tradiciones del desierto encuentra el esquema «culpa-castigoarrepentimiento-salvación», esquema tan ampliamente usado por el Dtr en el libro de los Jueces. Lo mismo cabe decir de las tradiciones sinaíticas, cuyas afinidades, según él, con el Deut y el Dtr son indudables. Las tradiciones del Sinaí no se explican bien, si no es en relación con el Deut.

Las promesas patriarcales son, en general, adiciones redaccionales. Gen 15 depende de Is 7. La mención de la alianza y la descripción de los confines de la tierra prometida es propia de la literatura afín al Deut y al Dtr. Por lo demás, las promesas patriarcales: promesa de la tierra, bendición y multiplicación de la descendencia sólo son concebibles cuando estos bienes ya no son evidentes.

14. V. FritZ, Israel in der Wüste. Traditionsgeschichtliche Untersuchung der Wüstenüberlieferung des Jahwisten. Marburg, 1970.

15. L. PerlitT, Bundestheologie im Alten Testament, WMAnt, 36. Neukirchen, 1969; E. ZENGER, Die Sinaitheophanie. Untersuchungen zur Jahwistischen und elohistischen Gesamtwerke. FzB, 3. Würzburg, 1971; A.R. REICHERT, Der Jehowist und die sogenannten deuteronomistischen Erweiterung in Buch Exodus. Tübingen, 1972. 
Finalmente añade otro argumento: el silencio de los profetas sobre las tradiciones del Pentateuco. El Sinaí no es mencionado antes del Deut. Sólo Amós y Oseas conocen algo de las tradiciones patriarcales y del Éxodo, pero Isaías y Miqueas ignoran ambas cosas. Sólo el Deut, el Dtr, los profetas y los salmos posexílicos conocen a Moisés. En general, puede decirse que los textos preexílicos ignoran prácticamente todo el Pentateuco a excepción de Amós y Oseas. En Judá no debieron ser conocidas estas tradiciones, si no es después de la destrucción de Jerusalén. Su conclusión no puede ser más rotunda: el J, su teología, su concepción de la historia debe colocarse en relación con el Deut. Con su obra el $\mathbf{J}$ intenta sostener la fe en un tiempo en que se encuentra en peligro, ya real o muy probable. Situación lamentable, que el J interpreta como juicio divino por las culpas pasadas.

Schmidt es consciente de la novedad que propone. Por eso lo hace en un libro con un título dubitativo y que quiere servir de base de discusión. Hay que tener en cuenta que no se trata sólo de una manera distinta de fechar al J, sino de una nueva concepción de la historia y teología de Israel. Según esto, los profetas no serían continuadores de la teología de la historia de Israel, sino sus inspiradores. Fácilmente se nota la coincidencia en muchos puntos con J. van Seters: a ambos autores los conceptos e ideas del $\mathbf{J}$ parecen muy recientes y se les hace imposible creer que remonte a la época salomónica.

Después de la lectura del libro, uno se pregunta si Schmidt no acentúa excesivamente los paralelismos con la literatura deuteronómica, ocultando las diferencias. Después de un siglo en que se ha repetido hasta la saciedad que el estilo e ideas del Deut son muy peculiares y características, venir ahora diciendo que el $\mathbf{J}$ es también deuteronómico, es convertir el deuteronomismo en una panacea que resuelve todo y no explica nada. Los antropomorfismos al hablar de Dios ciertamente no comulgan muy bien con la teología del nombre de Dios, propia del Deut. Igualmente habría que decir que el estilo libre y suelto del J contrasta bastante con el estilo ampuloso, solemne y redundante de la prosa deuteronómica. Por lo demás, difícilmente uno se imagina a un autor influenciado por el Deut, escribir sin escrúpulo el relato de la serpiente levantada en el desierto por Moisés.

Quizá de los análisis de Schmidt sea más fácil concluir que en el $\mathrm{J}$ hay partes recientes, textos que no pueden ser del $\mathrm{J}$ salomónico, que reducirle todo él a un escrito tardío. 


\section{3) La opinión de R. Rendtorff ${ }^{16}$}

A nuestro juicio el ataque más serio contra la hipótesis documentaria es el efectuado por R. Rendtorff. El libro es fruto de una larga dedicación al tema ${ }^{17}$. Ya en 1965 se había esforzado en colmar el abismo que se había abierto entre la escuela escandinava partidaria de una tradición oral como suficiente explicación del Pentateuco y la teoría wellhauseniana, que habla de documentos o fuentes. En 1969, su posición frente a la teoría documentaria se acentúa. En él estudio de la composición del Pentateuco, decía, se han empleado dos métodos diferentes que han complicado el tema. La crítica literaria parte del final, del estado actual del texto, en el que sorprende divergencias de estilo, vocabulario, etc. y concluye con la hipótesis documentaria como explicación de este fenómeno. De otra parte, Gunkel con su método de Historia de las Formas parte de las «pequeñas unidades». A este método se viene a sumar la historia de la tradición que tendría por objeto estudiar el proceso de formación del Pentateuco desde las pequeñas unidades a las grandes unidades o complejos literarios para terminar en el estado actual. Ya en aquella ocasión Rendtorff reprochaba a M. Noth no haber sido consecuente con su método histórico tradicional, ya que, según él, pasa de las pequeñas unidades a los temas del Pentateuco. El estadio intermedio, es decir, la formación de las unidades mayores a partir de las pequeñas, fue dejado en el olvido. Nadie ha estudiado cómo se formó el ciclo de Abrahán, o el de Jacob, o la tradición de la salida de Egipto a partir de las pequeñas unidades, ni tampoco nadie se ha interesado en investigar por qué estas unidades se han unido entre sí, porque, -y esto es lo que observa Rendtorff y esta observación tendrá mucha importancia en su rechazo de la hipótesis documentaria- en la historia de Moisés la tierra es mencionada por vez primera en Ex 3,8 y se la presenta como tierra desconocida, sin aludir para nada a la promesa de la tierra que tantas veces ocurre en las tradiciones patriarcales. De aquí que concluya que estas unidades (Historia patriarcal, Éxodo, Sinaí, etc.) son unidades independientes entre sí. En 1974 precisaría que es difícil conciliar los estratos paralelos de que habla la hipótesis documentaria con los complejos de tradiciones de los que trata $\mathrm{G}$. von Rad, cada uno de los cuales contiene un solo tema. Entre estos complejos

16. R. RENDTORFF, Das überlieferungsgeschichtliche Problem des Pentateuch. BZAW, 147. Berlín, 1977.

17. R. RENDTORFF, «Literarkritik und Traditionsgeschichte»: Evangelische Theologie, 27 (1967) 138-153; «Tradition-historical Method and the Documentary Hypothesis»: Proceedings of the Fifth World Congress of Jewih Studies. Jerusalem, 1969, I, 5-11; «Der 'Jahwist'als Theologe? Zum Dilemma der Pentateuchkritik: Supplement to Vetus Testament, 28. Leiden 1975, 158-166. 
'de tradiciones él no sorprende estructuración teológica alguna, por lo que niega la existencia del J. Una vez más insiste en el silencio de Ex 3,8.

En el libro publicado en 1977 concreta algunas cosas y desarrolla otras con una argumentación más cerrada y severa.

En la primera parte encontramos ideas ya apuntadas en los artículos que el autor había publicado antes: incompatibilidad entre la crítica literaria y el método histórico tradicional, la acusación dirigida a Noth de no haber realizado el programa de la Formgeschichte, etc. Rendtorff precisamente quiere hacer el estudio de los grandes complejos a partir de las pequeñas unidades. Reconoce en el Pentateuco cinco grandes complejos: Historia primitiva, Patriarcas, Moisés y Éxodo, Sinaí, marcha por el desierto. Notemos entre paréntesis el parecido con los temas del Pentateuco según Noth. Nota Rendtorff que cada uno de estos grandes conjuntos es considerado hoy por todos como unidades cerradas, más o menos independientes; pero, a pesar de ello, todos entienden cada uno de estos conjuntos como parte de otros, a través precisamente de la continuidad de las fuentes. Con ello no se mantiene la singularidad e independencia de cada complejo. Metodológicamente sería mejor examinar la elaboración de cada uno de estos conjuntos, sin que intervenga para nada la repartición del texto en fuentes. Sólo en segundo lugar se podría intentar la búsqueda de alguna coherencia entre los complejos literarios.

Este método emplea él y escoge como ejemplo las tradiciones patriarcales. Éstas constituyen para él una unidad mayor, integrada por pequeñas unidades sueltas o relatos que forman entre sí pequeños ciclos o Sagenkränze. La heterogeneidad de los relatos es evidente, pero al mismo tiempo el lector obtiene de su lectura una impresión de coherencia en toda la narración. ¿Será ello debido a un plan concebido y planeado? Y si es así, ¿cuáles son las características de esta unidad?, ¿con qué medios se formó? Él mismo se responde, diciendo que si hay algún elemento unificador, éste debe buscarse en las promesas patriarcales que salpican los relatos. En el estudio de las promesas patriarcales se detiene largamente examinando una por una: promesa de la tierra, de descendencia, de bendición (que primitivamente no era una promesa), de asistencia divina y de un hijo. Este examen lo hace siguiendo el método histórico tradicional, prescindiendo de la distribución en fuentes. El resultado que obtiene es el siguiente: las promesas se encuentran asociadas de manera muy diversa. Una promesa dirigida al patriarca en singular se ha extendido a la descendencia, lo que ha provocado que se introduzca una promesa de descendencia numerosa. Otras veces sucede de diferente manera. Esta extrema variedad de fórmulas de las promesas le permite afirmar que estas promesas han sido reelaboradas, reinterpretadas teológicamente en diferentes estadios de la transmisión. 
Pasa luego a examinar la función de las promesas en la composición del Pentateuco. La única función que les reconoce es servir de marco a los ciclos de cada patriarca y a su unión entre sí. En la historia de Isaac, la promesa de asistencia divina se halla en dos discursos de Yahvé, uno al comienzo y otro al final. En la historia de Jacob se halla tres veces: al comienzo $(28,15)$ en el medio $(31,3)$ y al final $(46,2-4)$. En el ciclo de Abrahán se halla al comienzo y al final $(12,1$ y 22). Esta asistencia divina es un elemento redaccional que ha servido para enmarcar y unir los tres ciclos.

Un segundo elemento, la bendición para otros, sirve de lazo de unión entre los ciclos. En la historia de Abrahán está al comienzo $(12,3)$ y al final $(22,18)$. En los ciclos de Isaac y Jacob, al comienzo $(26,4 ; 28,14)$. Dada la distinta formulación de la bendición para otros, cree poder afirmar que los ciclos de Abrahán y Jacob fueron los primeros que se unieron: Gen 12,3 y 28,14 son más antiguos que Gen 22,18 y 26,4. En una segunda fase se incluyó en medio de los dos, el ciclo de Isaac también mediante la promesa de bendición para otros, pero formulada diferentemente, con una fraseología que recuerda la del Deut. Estas distintas reelaboraciones se hicieron de manera diversa en cada ciclo. En la historia de Abrahán las promesas entraron profundamente en los relatos; en las de Jacob se manifiestan como un elemento de composición; en Isaac solamente salen en dos lugares sin relación con el contexto.

Rendtorff cree encontrar así muchos estratos en las tradiciones patriarcales; pero nunca afirma si estos estratos se colocan a nivel de transmisión oral o algunos de ellos pertenecen ya a la transmisión escrita. En todo casọ, parece que esta unión entre ciclos y una parte considerable de las promesas es fruto de una actividad literaria. Se podría decir que la historia patriarcal se compone de una serie de relatos independientes sucesivamente reelaborados en muchos estratos y unidos entre sí extrínsecamente. La única unión redaccional unitaria observable es la del Deut.

Pasa luego a examinar las tradiciones del Éxodo y constata que no existe en estas tradiciones una elaboración hecha con la misma intención y con los mismos medios. No hay discursos de promesas en el Exodo. Cuando en Ex 3,8 se menciona a la tierra a la que Dios va a llevar a los israelitas, ésta se presenta como desconocida. Este silencio de Ex 3,8 es la mayor dificultad que presenta Rendtorff para poder admitir una redacción continua de los complejos pertenecientes al Pentateuco. Para él, resulta inevitable afirmar que las tradiciones mosaicas han sido elaboradas bajo otros puntos de vista e intenciones que las tradiciones patriarcales. Cada gran unidad del Pentateuco goza de gran independencia y desde luego la elaboración que han sufrido las tradiciones patriarcales no es visible en el resto del Pentateuco. Hay, ciertamente, una elaboración que aparece en algunas frases ocurrentes aquí y allá sobre «la tierra que 
juró Yahvé dar a sus padres», redacción extrínseca a los relatos, que presupone los ciclos ya existentes y que recuerdan indudablemente al Deut. Como no sorprende una redacción anterior a esta última, el $\mathrm{J}$ de la hipótesis documentaria no tiene sentido.

A continuación somete estos resultados negativos a una contraprueba: examina si el $\mathbf{J}$ tiene consistencia. Para ello recoge las opiniones que hay sobre el $\mathbf{J}$ entre los partidarios de la hipótesis documentaria. Dibuja un cuadro tan lamentable del $\mathrm{J}$ que nadie, después de haber leído esta sección, querrá hacerse partidario del $\mathrm{J}$ : unos sorprenden varios estratos en el $\mathrm{J}$; no hay coincidencia en la asignación de versículos al J, sobre todo a partir del Éxodo; tampoco se sabe si el $\mathbf{J}$ tiene o no tiene historia de la conquista; acerca de la parte del $\mathbf{J}$ en la tradición del Sinaí reina una absoluta confusión; y finalmente se caen en tantas contradicciones a la hora de juzgar el vocabulario y el estilo del J que es mejor abandonarlo. El J, según él, se sigue manteniendo por inercia. Cuando se examinan de cerca las razones para defender al $\mathbf{J}$, éstas son tan frágiles que el mismo $J$ es un fantasma. Solamente hay unanimidad en la asignación de parte de la historia primitiva y Gen 12,1-3 al J. Pero aún este último texto es discutido por Rendtorff. Gen 12,1-3, que se considera por todos como perteneciente al $\mathrm{J}$, no contiene ninguna promesa independiente y distinta de las que ocurren en los demás lugares y ellas pertenecen a diversos estratos.

Recojamos, por último, la opinión que tiene de P. Reconoce que hay elementos típicos de P, pero ellos sólo se encuentran en Gen 1-Ex 14. Estos elementos no pertenecen a un documento. En concreto distingue dos grupos de textos: la indicación de la edad de los patriarcas en una determinada etapa de su vida y la indicación de la edad al momento de la muerte. Los dos literariamente son independientes. Niega también que Gen 23 pertenezca a P. Prácticamente solo le deja Gen 17. La conclusión mejor sería, según él, no hablar de documento $\mathrm{P}$, sino de adiciones y comentarios. En definitiva Rendtorff se acercaría a una hipótesis fragmentaria por lo que se refiere a $P$.

¿Qué decir de una hipótesis tan resolutiva? Desde luego, debe notarse que Rendtorff es más serio enemigo de la hipótesis documentaria que los dos autores anteriormente citados. J. van Seters y Schmidt no niegan la existencia de J. Solamente que retardan mucho su composición. Para Rendtorff, en cambio, el $\mathrm{J}$ es una fantasía de los estudiosos modernos.

Los tres coinciden en sacar sus conclusiones del examen particular de una sección. Schmidt saca su opinión del análisis de la vocación de Moisés; J. van Seters se fija sólo en la tradición de Abrahán; y Rendtorff, en las promesas patriarcales. En los tres casos, ¿no es escasa la base para sacar conclusiones tan amplias?

Pero, además, en la hipótesis de Rendtorff encontramos puntos oscuros. 
De un lado afirma que el ciclo de Abrahán y el ciclo de Jacob fueron unidos entre sí redaccionalmente $(12,3$ y 28,14$)$; solamente después en un estadio ulterior de elaboración de la tradición se incluyó entre las dos la historia de Isaac $(22,8$ y 26,4$)$. Estos dos últimos lugares, según él, están emparentados con el Deut. Habría que preguntarse entonces a qué redacción pertenece Gen 12,3 y 28,14 , que, según él, son parte de una elaboración anterior.

De otra parte, concede que Gen 12,1-3 une la historia primitiva con las tradiciones patriarcales, pero precisa que sólo a éstas y no al resto del Pentateuco. Ciertamente esta afirmación resulta sorprendente. No se imagina uno fácilmente, para qué el $\mathrm{J}$ antepone una introducción tan grandiosa, si todo va a terminar con Jacob en la región de Betel.

Nos parece además que Rendtorff infravalora la crítica literaria: las promesas son analizadas sin extenderse en el contexto en que están incluidas. De este modo no es extraño que no encuentre lazo de unión entre ellas. Trabajando así, lo raro será encontrar unión estrecha entre los diversos relatos. Y es que Rendtorff da por supuesto, como muchos otros, que los relatos pequeños son unidades independientes entre sí, sin ninguna relación mutua, procedentes en su mayor parte del folklore. Ante este punto de vista habría que preguntarse seriamente, si ello no es un presupuesto que grava enormemente las investigaciones del Pentateuco. La lectura de la sección V del libro de A. de Pury ${ }^{18}$ permite adivinar otro punto de vista bien diferente: las unidades pequeñas están muy frecuentemente unidas en un ciclo y son apreciadas, no por su carácter folklórico, sino porque son narraciones de los antepasados.

Finalmente, Rendtorff sobrevalora el silencio de Ex 3,8. ¿Necesitaba recordar el $\mathrm{J}$ a qué tierra se refiere, cuando acababa de hablar de ella desde la misma vocación de Abrahán (Gen 12,1-3)?

La composición del Pentateuco ha vuelto a recuperar el protagonismo que tuvo en épocas pasadas, ya lejanas. Cabe esperar que ello contribuya a una mejor inteligencia de las tradiciones religiosas de Israel. Resulta, no obstante, dudoso que las opiniones aquí referidas supongan el fin de la hipótesis documentaria. Han hecho ciertamente algo bueno: mantener viva la conciencia de que la hipótesis documentaria es una pura hipótesis y, como tal, explica unas cosas y deja otras sin aclarar. La hipótesis más coherente será la que recoja el mayor número de sufragios. El final del camino, hoy por hoy, no se ve. Cabe adivinar, sin embargo, que en el futuro se intente rejuvenecer algunos

18. Véase la nota 9. 
relatos atribuidos hasta hoy al J. O lo que es igual: dar mayor cuerpo al RJE, es decir, a la redacción Jehovista, como opina P. Weimar ${ }^{19}$. Esto sería acercarse a algunas de las exigencias de H.H. Schmidt y J. van Seters.

C. Mielgo

19. P. WeIMAR, Untersuchungen zur Redaktionsgeschichte des Pentateuch. BZAW, 146. Berlín, 1977. 